Revista de Metalurgia 52(4)

Octubre-Diciembre 2016, e084

ISSN-L: 0034-8570

doi: http://dx.doi.org/10.3989/revmetalm.084

\title{
Desarrollo de las aleaciones de titanio y tratamientos superficiales para incrementar la vida útil de los implantes
}

\author{
Joan Lario-Femenía ${ }^{\bowtie}$, Angélica Amigó-Mata, Ángel Vicente-Escuder, Francisco Segovia-López, \\ Vicente Amigó-Borrás \\ Universitat Politècnica de València, Instituto de Tecnología de Materiales, Camino de Vera s/n, 46022 Valencia \\ Autor para la correspondencia joalafe@posgrado.upv.es
}

Enviado: 7 Octubre 2016; Aceptado: 14 Noviembre 2016; Publicado on-Line: 19 Diciembre 2016

\begin{abstract}
RESUMEN: El envejecimiento de la población junto con el incremento de la esperanza de vida, obligan al desarrollo de prótesis que presenten un periodo de vida útil cada vez mayor. El éxito clínico de los implantes está basado en la consecución de la osteointegración. Por lo tanto, las prótesis metálicas necesitan disponer de una compatibilidad mecánica con el hueso que sustituyen, que se consigue mediante una combinación de bajo módulo elástico, alta resistencia a la rotura y a fatiga. La mejora, a corto y largo plazo, de la osteointegración es función de múltiples factores, de entre los cuales son de gran importancia su diseño macroscópico y dimensional, el material y la topografía superficial del implante. Este artículo se centra en resumir las ventajas que presentan el titanio y sus aleaciones para ser empleadas como biomateriales, y la evolución que han sufrido estas, en las últimas décadas, para mejorar su biocompatibilidad. En consecuencia, se ha recapitulado la evolución que han sufrido los implantes, resumiéndose a través de tres generaciones. En los últimos años se ha incrementado el interés en los tratamientos superficiales de las prótesis metálicas, con el objetivo de alcanzar una integración del tejido óseo duradera y en el menor tiempo posible. En este artículo se exponen varios tratamientos superficiales utilizados actualmente para modificar la rugosidad o para obtener recubrimientos superficiales; cabe destacar la oxidación electroquímica con tratamiento térmico, para modificar la estructura cristalina de los óxidos de titanio. Tras la revisión bibliográfica llevada a cabo para la redacción de este artículo, las aleaciones $\beta$ de titanio, con una superficie de nanotubos obtenida mediante oxidación electroquímica y una etapa posterior de tratamiento térmico para obtener una estructura cristalina, son la opción de futuro para mejorar la biocompatibilidad a largo plazo de las prótesis de titanio.
\end{abstract}

PALABRAS CLAVE: Aleaciones $\beta$ de titanio; Anodizado; Biocompatibilidad; Nanotubos; Osteointegración; Tratamientos superficiales; Tratamiento térmico

Citation / Cómo citar este artículo: Lario-Femenía, J., Amigó-Mata, A., Vicente-Escuder, A., Segovia-López, F., AmigóBorrás, V. (2016) "Desarrollo de las aleaciones de titanio y tratamientos superficiales para incrementar la vida útil de los implantes". Rev. Metal. 52(4):e084. doi: http://dx.doi.org/10.3989/revmetalm.084

ABSTRACT: Development of titanium alloys and surface treatments to increase the implants lifetime. The population aging together with increase of life expectancy forces the development of new prosthesis which may present a higher useful life. The clinical success of implants is based on the osseointegration achievement. Therefore, metal implants must have a mechanical compatibility with the substituted bone, which is achieved through a combination of low elastic modulus, high flexural and fatigue strength. The improvement, in the short and long term, of the osseointegration depends on several factors, where the macroscopic design and dimensional, material and implant surface topography are of great importance. This article is focused on summarizing the advantages that present the titanium and its alloys to be used as biomaterials, and the development that they 
have suffered in recent decades to improve their biocompatibility. Consequently, the implants evolution has been recapitulated and summarized through three generations. In the recent years the interest on the surface treatments for metallic prostheses has been increased, the main objective is achieve a lasting integration between implant and bone tissue, in the shortest time possible. On this article various surface treatments currently used to modify the surface roughness or to obtain coatings are described it; it is worthy to mention the electrochemical oxidation with post-heat treated to modify the titanium oxide crystalline structure. After the literature review conducted for prepare this article, the $\beta$ titanium alloys, with a nanotubes surface of obtained by electrochemical oxidation and a subsequent step of heat treatment to obtain a crystalline structure are the future option to improve long term biocompatibility of titanium prostheses.

KEYWORDS: Anodization; $\beta$ titanium alloys; Biocompatibility; Nanotubes; Osseointegration; Surface treatments; Thermal treatments

Copyright: (C) 2016 CSIC. Este es un artículo de acceso abierto distribuido bajo los términos de la licencia Creative Commons Attribution (CC BY) España 3.0.

\section{INTRODUCCIÓN}

En Octubre de 2007, la Unión Europea (UE) adoptó una estrategia basada en promover la salud en una población que va envejeciendo gradualmente. En la Fig. 1 aparecen representadas las pirámides demográficas de España en el año 1995 y 2015. Se observa que la parte inferior se está cerrando debido a la baja tasa de maternidad, mientras que la parte superior se está expandiendo por un incremento de la esperanza de vida y una baja tasa de mortalidad. El enfoque estratégico de la UE se basa en reconocer los vínculos entre la salud, la promoción de los sistemas sanitarios dinámicos, la

(a)

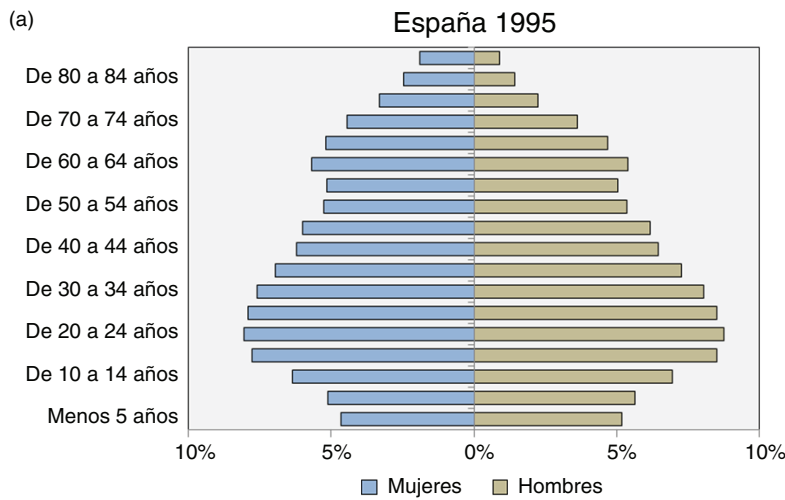

(b)

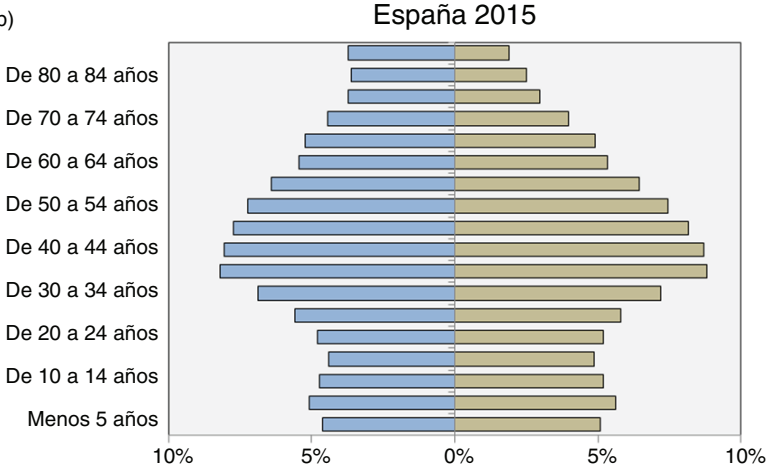

Figura 1. Pirámides demográficas española: a) Año 1995 y b) Añ̃o 2015. prosperidad económica y la integración de la salud en todas sus políticas.

El envejecimiento de la población tiene unas consecuencias sociales y económicas importantes. Las mayores necesidades de tratamientos médicos se deben a que cada vez más se alcanzan edades más elevadas ligadas a un aumento de la esperanza de vida y con ello al del gasto sanitario. En la Fig. 2 se muestra la cantidad de intervenciones médicas realizadas para atender fracturas, cada 10.000 habitantes, en función de la edad del paciente (National Center for Health Statistics, 2015). Se observa que a medida que se incrementa la edad del paciente aumenta la probabilidad de sufrir una intervención. En la Fig. 3 se puede observar que en España existe durante el periodo 2004 a 2012, una relación entre el aumento del gasto sanitario y el aumento de la esperanza de vida.

Una condición importante para que las personas envejezcan activamente es que disfruten de un buen estado de salud (18th CEIES Seminar, 2002). Se entiende como envejecimiento activo aquel proceso con el que se mejora la calidad de vida con la edad, permitiendo que las personas presenten un bienestar físico, social y mental para poder participar en la sociedad de acuerdo con sus necesidades, deseos y capacidades.

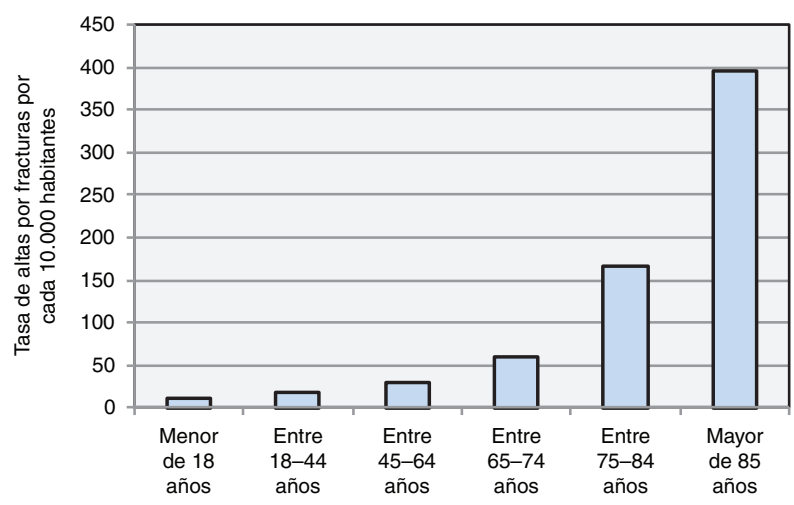

FIgURA 2. Tasa de altas por fracturas por cada 10.000 habitantes. Adaptado de: National Center for Health Statistics (2015). 
Bjursten et al. (2010) resaltaron la importancia de incrementar la unión del implante al hueso, dado que la vida media de un implante ortopédico está comprendido entre los 10-15 años, lo que implica que los pacientes deben de someterse a dificultosas operaciones de revisión, con largos periodos de rehabilitación. El envejecimiento de la población junto con el incremento de la esperanza de vida, obligan al desarrollo de implantes quirúrgicos y materiales que presenten un periodo de vida útil cada vez mayor.

El aumento de la productividad y la reducción de costes en la sanidad dependen de la mejora de los métodos de diagnóstico y quirúrgicos, entre los que se englobarían las mejoras en las prótesis y la innovación en fármacos. Así pues es importante desarrollar nuevas prótesis con mayores tasas de osteointegración, que presenten un periodo de vida útil superior, reduzcan el tiempo de recuperación y de hospitalización, y el de revisión quirúrgica. Lo anterior podrá prevenir, retrasar y minimizar la dependencia de la población de edad avanzada y reducir, así, los costes de protección social.

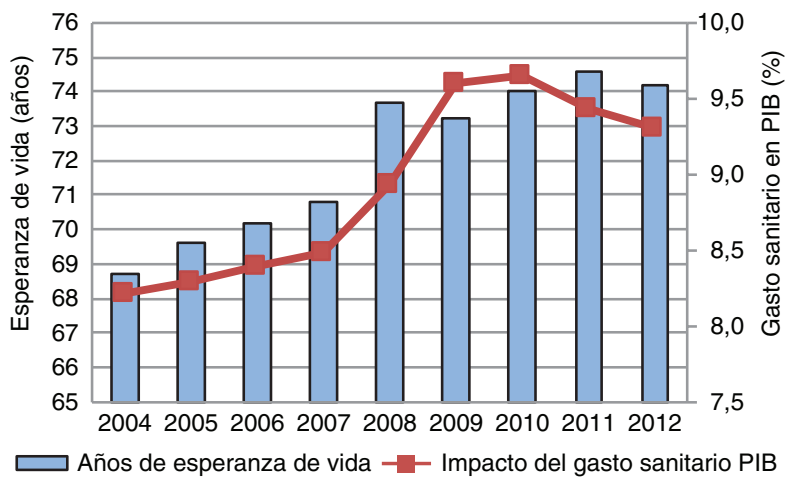

Figura 3. Evolución de la esperanza de vida y gasto sanitario en España en periodo comprendido entre 2004-2012.
La principal problemática en la sustitución de una prótesis, es que el hueso receptor se encuentra más deteriorado, presentando menores tasas de osteointegración. Por ello, es importante desarrollar nuevos materiales y tratamientos superficiales que aumenten la vida útil, mejoren la biocompatibilidad y pospongan las revisiones.

Los metales presentan elevadas propiedades mecánicas y físicas. Entre las principales a considerar en la selección del material, están la resistencia máxima a la rotura, el módulo elástico, el límite de resistencia a fatiga, las resistencias al desgaste y a la corrosión (Long y Rack, 1998; Okazaki y Gotoh, 2005; Niinomi, 2008). Las prótesis metálicas no solo necesitan disponer de una compatibilidad mecánica con el hueso que sustituyen, que se consigue mediante una combinación de bajo módulo elástico, una alta resistencia a la rotura y una elevada resistencia a la fatiga, sino que también deben de presentar una elevada biocompatibilidad. En la Fig. 4 se resumen los requisitos que deben cumplir los materiales para poder ser empleados como implantes.

Uno de los requisitos de biocompatibilidad de las prótesis metálicas es que posean unas propiedades físico-mecánicas que les permitan reemplazar o restaurar la función de un tejido del cuerpo, ya que están en contacto de manera continua o intermitente con fluidos corporales, y no deben provocar una respuesta adversa en el huésped (Niinomi, 1998).

El éxito clínico de los implantes está basado en la consecución de la osteointegración, es decir, la conexión directa estructural y funcional entre el hueso vivo y su superficie. La mejora, a corto y largo plazo, de la osteointegración es función de múltiples factores, de entre los cuales, su diseño macroscópico y dimensional, el material y la topografía superficial del implante son de gran importancia.

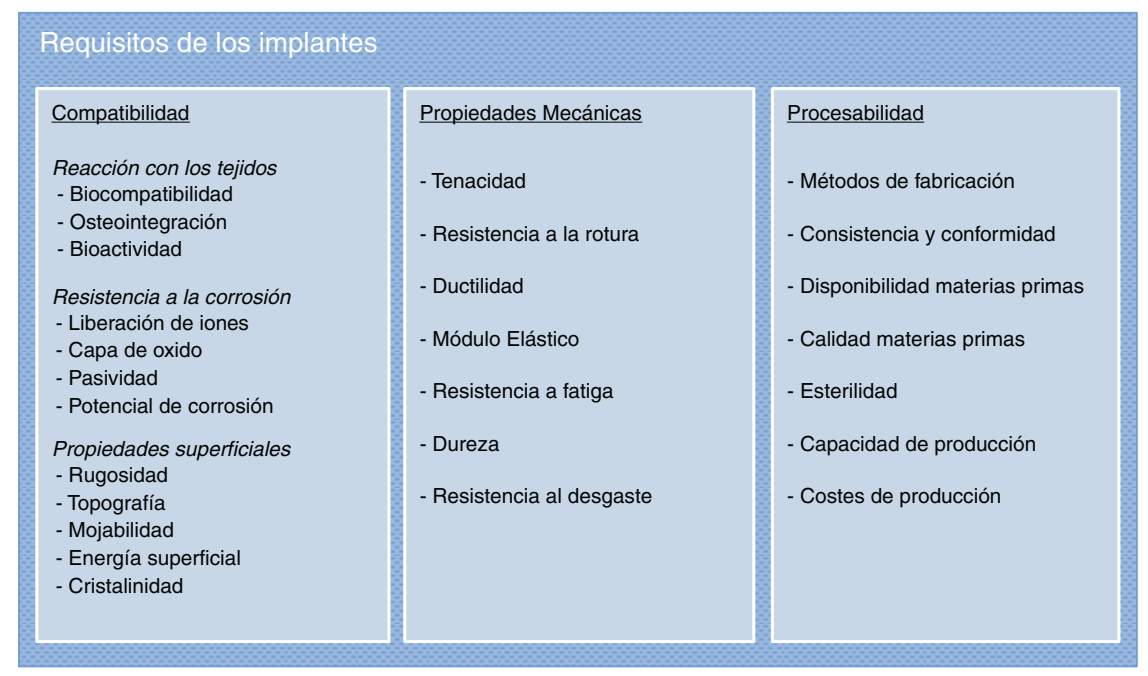

FIGURA 4. Requisitos de los implantes para aplicaciones ortopédicas (Niinomi, 1998). 


\section{EL TITANIO COMO BIOMATERIAL}

El empleo generalizado, como biomaterial, del titanio y sus aleaciones en la fabricación de implantes se debe a que cumplen los requerimientos de biocompatibilidad, osteointegración, propiedades mecánicas, resistencia la corrosión, procesabilidad y disponibilidad. La elevada osteointegración es debida a que cuando se implanta en un tejido duro, el hueso es capaz de crecer en contacto directo con el implante, sin una apreciable cápsula de tejido blando a su alrededor.

Estas aleaciones presentan un módulo elástico y una densidad menor que los aceros inoxidables o las aleaciones de $\mathrm{Co}-\mathrm{Cr}$ utilizados como biomateriales. Se disminuye así un posible efecto de atrofia o reabsorción ósea en el hueso cercano al biomaterial implantado (Ryan et al., 2006; Niinomi, 2008).

Además, presentan una alta resistencia a la corrosión, gracias a la capa de óxido que se forma en la superficie de la aleación al entrar en contacto con el oxígeno, protegiéndola y evitando que se siga oxidando. Esta capa de óxido, asimismo, actúa como barrera protectora para evitar la cesión de cualquier tipo de ion desde el interior del metal hacia el medio fisiológico. El crecimiento celular está influenciado por la liberación de iones y partículas de los materiales empleados como implantes, como consecuencia de procesos de corrosión (Cremasco et al., 2011).

La microestructura de las aleaciones de titanio es el resultado de una serie de transformaciones sólido-sólido. Un elevado número de estudios han demostrado que la microestructura de las aleaciones tiene una influencia en las propiedades mecánicas (Sieniawski et al., 1997; Ahmed y Rack, 1998; Lütjering, 1998; Semiatin et al., 2002; Lee y Chen, 2013). En el caso de las aleaciones de titanio, la modificación de la microestructura mediante varios procesos como envejecimiento, tratamientos de solución, temple, forja, etc. han provocado considerables cambios en la resistencia a la rotura, resistencia a la flexión, fatiga, propagación de grietas, dureza, desgaste, corrosión y módulo elástico.

\section{EVOLUCIÓN DE LAS ALEACIONES DE TITANIO}

En lo que se refiere a las aleaciones de titanio, a principio de los años 80 , tras la aparición de las aleaciones de Ti-6Al-4V como prótesis de articulaciones, aparecieron estudios científicos en los que se destacaba la existencia de elevadas concentraciones de partículas de vanadio en los tejidos cercanos a la zona del implante. La presencia de dichas partículas es tóxica, pudiendo tener efectos carcinogénicos, así como interferencias con reacciones sistemáticas del cuerpo (Niinomi, 1998; Okazaki y Gotoh, 2005).
A causa de los problemas de toxicidad a largo plazo que puede presentar el vanadio, en los años 80 se desarrollaron también las aleaciones Ti-6Al-7Nb, que presentan microestructuras y propiedades similares a la Ti-6Al-4V. El vanadio se vio sustituido por niobio para estabilizar la fase $\beta$ en valores cercanos a la temperatura ambiente. Mediante esta modificación de la composición química de la aleación se consigue mejorar la resistencia a la corrosión y biocompatibilidad de las aleaciones $\alpha+\beta$ (Iijima et al., 2003; Chlebus et al., 2011; Nguyen et al., 2013; Ossowska et al., 2014).

La composición de la capa de óxido en las aleaciones de titanio está influenciada por elementos individuales que la conforman, que debido a los procesos de rozamiento y corrosión entran en contacto con las células y fluidos del cuerpo. Por lo tanto, no solo se tienen que estudiar la biocompatibilidad de las aleaciones sino también de los elementos individuales por separado. Eisenbarth et al. (2004) estudiaron la biocompatibilidad de los elementos estabilizantes de la fase $\beta$ del titanio. En su investigación demostraron la idoneidad de los elementos $\mathrm{Nb}$, $\mathrm{Ta}, \mathrm{Zr}$ para ser empleados como biomateriales.

A partir de los años 90 empezaron a desarrollarse gran variedad de aleaciones $\beta$, principalmente por su mayor resistencia a la fatiga y a la corrosión, así como su menor módulo de elasticidad en comparación con las aleaciones $\alpha+\beta$, para reducir la problemática del apantallamiento de tensiones y pérdida de masa ósea (Kuroda et al., 1998; Cremasco et al., 2008; Park y Bae, 2014).

Por tanto, el esfuerzo en los últimos años se ha centrado en el desarrollo de nuevas aleaciones tipo $\beta$ para su aplicación como implantes a partir de elementos de aleación biocompatibles como $\mathrm{Nb}$, Ta, $\mathrm{Zr}$ o Mo. Lee y Chen (2013) proponen el empleo de las aleaciones de titanio de la familia TNTZ para ser empleadas en implantes ortopédicos. Esta familia de aleaciones presenta un bajo módulo elástico, excelente resistencia mecánica, elevada resistencia

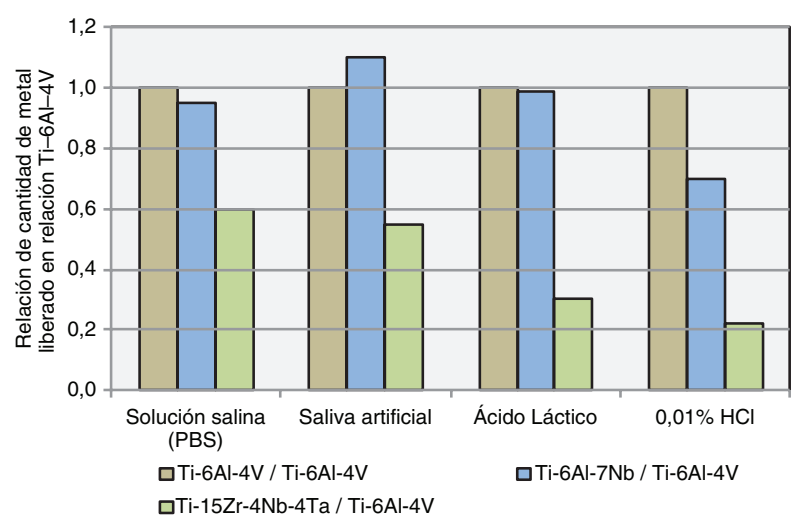

Figura 5. Cantidad de metal liberado en relación Ti-6Al-4V (adaptado de Okazaki y Gotoh, 2005). 
a la corrosión y están compuestas por elementos biocompatibles (Lee y Chen, 2013). Cremasco et al. (2011) demostraron en un estudio in vitro que las aleaciones de titanio que presentan $\mathrm{Nb}$, Ta y $\mathrm{Zr}$, como elementos estabilizantes de la fase $\beta$, no causan efectos tóxicos y presentan una elevada adhesión celular.

Las aleaciones de Ti-Nb-Ta poseen una mayor densidad de corriente de pasivación en comparación con Ti CP o Ti-6Al-4V. El aumento de la concentración de $\mathrm{Ta}$ y $\mathrm{Nb}$ en la formulación de la aleación disminuye la densidad de corriente de pasivación y cambia el potencial de corrosión en la dirección noble. Este hecho se produce por la naturaleza pentavalente del $\mathrm{Nb}$ y Ta, así como un radio similar al Ti que estabiliza la capa de óxido y disminuye la solubilidad en un ambiente oxidante (Okazaki y Gotoh, 2005). En la Fig. 5, aparece la cantidad de metal liberado por varias aleaciones de titanio, comparada con la aleación Ti-6Al-4V (Okazaki y Gotoh, 2005).

\section{EVOLUCIÓN DE LOS BIOMATERIALES}

La mayoría de los implantes fallan porque se pierde la interface entre el implante y el hueso, sugiriendo que existe una deficiente osteointegración que contribuye a su fallo (Bjursten et al., 2010). En los últimos años, se ha incrementado el interés en los tratamientos superficiales de las prótesis metálicas para mejorar la osteointegración. Estudios recientes han mostrado que dicho proceso está influenciado por la geometría y topografía de la superficie del implante (Ban et al., 2006; Brammer et al., 2009; Lee et al., 2013; Bayram et al., 2014). La modificación de la rugosidad y área superficial pueden proporcionar un medio más adecuado para la adsorción de proteínas y el crecimiento celular, acelerando el proceso de regeneración del hueso y mejorando a corto y largo plazo la osteointegración de los implantes (Kim et al., 2013; Jeong et al., 2014a).
Los biomateriales, entre los que destacan las aleaciones de titanio, empleados como implantes han evolucionado a través de tres generaciones. La primera generación estaban mecanizados para coincidir con las propiedades físicas del tejido al que sustituyen, con baja toxicidad y siendo biológicamente inertes. El implante debe de ser capaz de distribuir las fuerzas, de forma homogénea, en el tejido óseo circundante (Duraccio et al., 2015). Los implantes dentales en su diseño presentan una rosca, cuyo objetivo es transferir la carga a la mandíbula y proporcionar un anclaje mecánico para su estabilización en el hueso receptor. Las roscas del implante mejoran la estabilidad primaria, que es fundamental para evitar micromovimientos indeseables del implante hasta que se consigue la osteointegración. La alta resistencia mecánica, la tenacidad a la fractura y la biocompatibilidad son esenciales para esta aplicación. En la Tabla 1 aparece resumidas algunas de las propiedades mecánicas y la microestructura de varias aleaciones de titanio.

La segunda generación de implantes fue desarrollada para presentar carácter bioactivo a través de tratamientos superficiales. La modificación de la rugosidad y del área superficial pueden proporcionar un medio más adecuado para la adsorción de proteínas y el crecimiento celular, acelerando el proceso de regeneración del hueso y mejorando a corto y largo plazo la osteointegración de los implantes (Kim et al., 2013; Jeong et al., 2014a). Por lo tanto, la superficie de los implantes necesita de un tratamiento superficial para optimizar sus propiedades y mejorar su biocompatibilidad. Entre estos tratamientos destacan el arenado (Pypen et al., 1997; Cochran et al., 1998), grabado ácido (Diniz et al., 2002; Li et al., 2002; Ban et al., 2006) y los recubrimientos cerámicos (Lee et al., 2013), que mejoran la naturaleza bioactiva de las superficies de los biomateriales.

La tercera generación, la más reciente, intenta promover la respuesta celular a nivel molecular y

TABla 1. Propiedades mecánicas de las aleaciones de titanio para aplicaciones biomédicas (Niinomi, 1998)

\begin{tabular}{lcccc}
\hline Aleación & $\begin{array}{c}\text { Resistencia a } \\
\text { tracción (MPa) }\end{array}$ & Elongación (\%) & Módulo elástico (GPa) & Microestructura \\
\hline Ti CP Grado 2 & 345 & 20 & 102.7 & $\alpha$ \\
Ti CP Grado 4 & 550 & 15 & 104.1 & $\alpha$ \\
Ti-6Al-4V ELI & $860-965$ & $10-15$ & $101-110$ & $\alpha+\beta$ \\
Ti-6Al-7Nb & $900-1050$ & $8.1-15$ & 114 & $\alpha+\beta$ \\
Ti-13Nb-13Zr & $973-1037$ & $10-16$ & $79-84$ & $\beta$ \\
Ti-12Mo-6Zr-2Fe & $1060-1100$ & $18-22$ & $74-85$ & $\beta$ \\
Ti-15Mo & 874 & 21 & 78 & $\beta$ \\
Ti-35.3Nb-5.1Ta-7.1Zr & 596.7 & 19 & 55 & $\beta$ \\
Ti-29Nb-13Ta-4.6Zr & 911 & 13 & 80 & $\beta$ \\
\hline
\end{tabular}


mejorar el rendimiento del implante a largo plazo. Se centra en nuevos tratamientos superficiales con morfología a escala nanométrica, así como en el estudio de aleaciones de titanio con menor módulo elástico. Estudios in vitro han demostrado que las superficies con capas de óxido de titanio, con geometría de nanotubos o nanoporos, mejoran el crecimiento celular y el crecimiento óseo (Mîndroiu et al., 2010; Tan et al., 2012; Minagar et al., 2013; Han et al., 2014). Salou et al. (2015) realizaron un estudio comparativo de osteointegración de diferentes acabados superficiales en implantes en fémures de conejos. Se comparaba implantes mecanizados, implantes arenados con alúmina y atacados con ácido y nanoestructurados. Los resultados de los ensayos de extracción, contacto implante-hueso y crecimiento de hueso indicaron que las superficies con una matriz de nanotubos presentan una mejor osteointegración en el hueso que los implantes con superficies arenadas y grabadas con ácido, y mucho mejor que los implantes simplemente mecanizados (Salou et al., 2015). La mejora en la osteointegración de los implantes con superficie de nanotubos también fue estudiada por Bjursten et al. (2010). Estos estudios in vitro, en conejos, muestran un incremento del contacto entre el hueso y el implante, una mayor concentración en $\mathrm{CaP}$ en la superficie del implante y una mayor fuerza para separar el implante del hueso en aquellos implantes con superficie de nanotubos que las superficies arenadas (Fig. 6) (Bjursten et al., 2010).

Este tipo de geometrías pueden incorporar en su interior agentes bioactivos (antibióticos, bactericidas, Ca-P), que se liberan gradualmente en las cercanías del implante, mejorando la osteointegración a corto y largo plazo (Choe et al., 2010; Çalişkan et al., 2014; Xie et al., 2014). La liberación prolongada de medicamentos desde el implante permite atacar al foco de la infección, reduciendo la cantidad de medicamentos suministrados al paciente y minimizando la posibilidad de la toxicidad sistemática de los medicamentos. Dentro de los fármacos

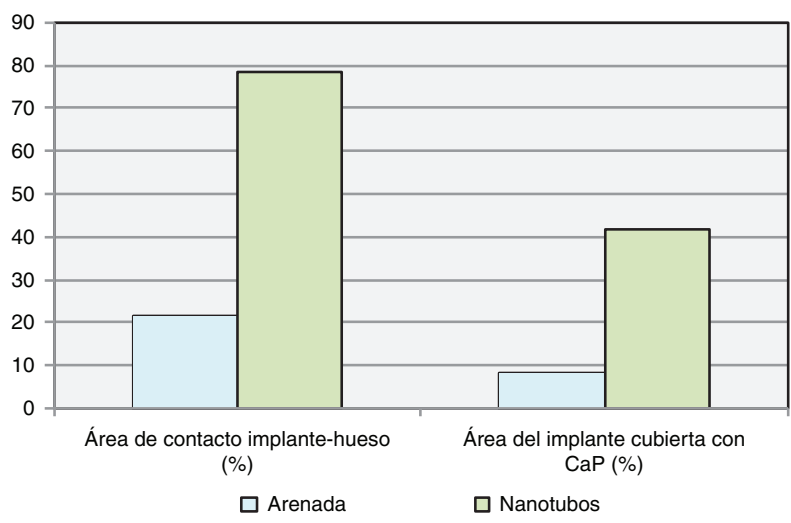

FIGURA 6. Evaluación de la Osteointegración para implantes con superficie arenada y con nanotubos (Bjursten, 2010). que pueden incorporarse en el interior de los nanotubos se encuentran aquellos que pueden combatir infecciones, reducir la inflamación y promover el crecimiento celular para la formación del hueso (Çalişkan et al., 2014).

\section{TRATAMIENTOS SUPERFICIALES}

Para llegar a alcanzar una integración del tejido óseo en el implante son necesarios varios meses. En los últimos años, se ha incrementado el interés en los tratamientos superficiales de las prótesis metálicas para mejorar la osteointegración. Estudios recientes han mostrado que dicho proceso está influido por la geometría y topografía de la superficie del implante (Anselme et al., 2000; Ban et al., 2006; Le Guéhennec et al., 2007; Hao et al., 2013). La modificación de la rugosidad y área superficial pueden proporcionar un medio más adecuado para la adsorción de proteínas y el crecimiento celular, acelerando el proceso de regeneración del hueso y mejorando a corto y largo plazo la osteointegración de los implantes (Mendonça et al., 2008; Jeon et al., 2014b; Salou et al., 2015). Por lo tanto, la superficie de los implantes necesita de un tratamiento superficial para optimizar sus propiedades y mejorar su biocompatibilidad. Existe una amplia variedad de técnicas que modifican la superficie de los implantes y en función de la rugosidad alcanzada, se pueden diferenciar en un rango macro, micro y nanométrico, dentro de las cuales existen a su vez subdivisiones.

Entre los primeros tratamientos superficiales empleados para obtener recubrimientos o modificar la rugosidad se pueden citar el plasma espray, el arenado, el tratamiento ácido y el sinterizado de polvos esféricos (Duraccio et al., 2015). Estos recubrimientos mejoran el crecimiento del hueso y afianzan el implante, si se compara con un implante sin tratamiento. La importancia de una topografía a escala micrométrica fue remarcada por Li et al. (2002) donde una rugosidad superficial de escala micrométrica, preparada por arenado y atacada con ácido, fue capaz de un rápido crecimiento óseo y aumentó el contacto entre hueso e implante. Sin embargo, estas superficies presentan una elevada rugosidad y porosidad que reducen el crecimiento celular en las primeras etapas de osteointegración (Le Guehennec et al., 2008).

Se ha observado que las superficies a escala nanométrica mejoran la función celular en los biomateriales, resultando en un mejor crecimiento y adhesión de las células osteoblásticas, de la formación de la matriz ósea y de la osteointegración (Kim et al., 2013; Salou et al., 2015). Das et al. (2009) estudiaron la influencia que tiene una morfología nanométrica en la interacción celular sobre la superficie del material, donde las superficies con morfología de nanotubos presentaban una mayor densidad 


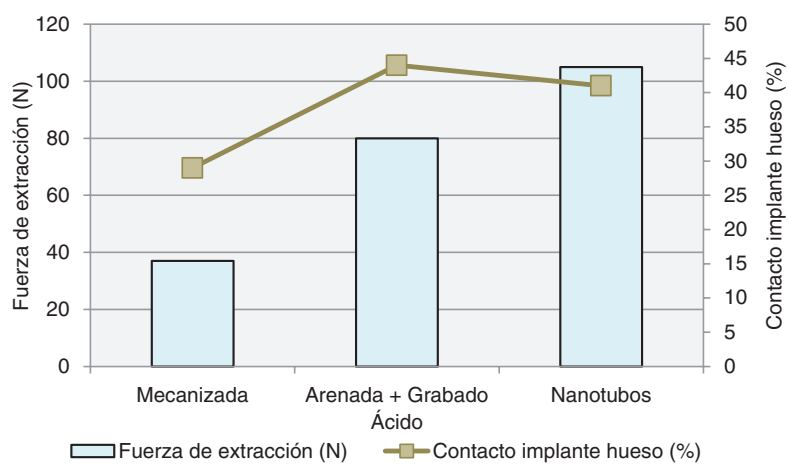

FigurA 7. Resultados de tres acabados superficiales implantados en cóndilos femorales de conejos NZW durante 4 semanas (Salou et al., 2015).

óptica que las superficies pulidas. Salou et al. (2015) demostraron, mediante el estudio en conejos citado, que el anclaje del hueso en una topografía de nanotubos era superior que en superficies mecanizadas o arenadas y grabadas con ácido (Fig. 7).

Dentro de los tratamientos superficiales se encuentran aquellas técnicas que permiten producir una capa de óxido, ampliamente utilizadas en las aleaciones de titanio. Entre las técnicas que se pueden emplear se destacan las gaseosas, microspark, CVD, químicas y electroquímicas. Sin embargo, algunos de estos métodos son complejos o requieren un elevado tiempo, por lo que se han descartado para su aplicación en el campo de la biomedicina. La oxidación electroquímica, entre estas técnicas, está centrando el interés de los investigadores, dado que permite obtener una capa superficial de óxido de titanio con estructura nanotubular, de forma rápida y con reducido coste (Bauer et al., 2011; Berger et al., 2011; Ferreira et al., 2013; Minagar et al., 2013; Çalişkan et al., 2014). A continuación se exponen, de forma resumida, algunas de las técnicas empleadas para modificar la superficie de las aleaciones de titanio empleadas como implantes.

\subsection{Proyección térmica}

La técnica de plasma espray o proyección térmica se puede definir como la aportación de materiales proyectados en forma de partículas fundidas finamente divididas, sobre un substrato debidamente preparado. El espesor de la capa formada debe de tener entre los 30-50 $\mu \mathrm{m}$ para ser uniforme, alcanzándose unos valores de rugosidad de alrededor de las $7 \mu \mathrm{m}$ e incrementándose el área superficial del implante (Duraccio et al., 2015).

\subsection{Arenado}

Otra alternativa para incrementar la rugosidad superficial de los implantes es la de arenarlos o granallarlos. Esta técnica consiste en proyectar partículas abrasivas, a alta presión, sobre la superficie del implante a tratar, generando una rugosidad del rango de $10 \mu \mathrm{m}$, empleándose como partículas abrasivas la alúmina $\left(\mathrm{Al}_{2} \mathrm{O}_{3}\right)$, titania $\left(\mathrm{TiO}_{2}\right)$ e hidroxiopatita, entre otras. La elevada rugosidad resulta en un anclaje mecánico entre el implante y la superficie del hueso. Esta técnica presenta el inconveniente de que las partículas proyectadas se incrustan en la superficie del implante, dejando un residuo que permanece incluso después de la limpieza con ultrasonidos, la pasivación ácida y la esterilización (Duraccio et al., 2015).

\subsection{Grabado ácido}

Por otra parte, los tratamientos ácidos permiten obtener superficies con microrugosidades, de alrededor de 0,5 a $4 \mu \mathrm{m}$ de tamaño de microcavidades poro (Ban et al., 2006; Le Guéhennec et al., 2007; Mendonça et al., 2008). Este tipo de rugosidades mejoran la unión entre el hueso y la superficie del implante, donde los implantes de titanio se ven atacados químicamente por ácidos fuertes durante periodos cortos de tiempo y a temperaturas inferiores a los $100^{\circ} \mathrm{C}$. Entre los ácidos más empleados se encuentran el ácido clorhídrico, sulfúrico, nítrico o fluorhídrico (Duraccio et al., 2015). El tratamiento ácido ha demostrado mejorar la osteointegración comparado con los implantes tratados por plasma espray o arenados (Ban et al., 2006; Le Guéhennec et al., 2008).

\subsection{Oxidación electroquímica}

Dentro de los tratamientos superficiales se encuentran las técnicas que permiten producir una capa de óxido, ampliamente utilizadas en las aleaciones de titanio. El titanio, igual que el resto de los metales de transición, es capaz de formar una capa de óxido en su superficie, por lo que pueden ser sometidos a tratamientos electroquímicos para la modificación de su superficie. Este tratamiento se puede realizar a través de una reacción de oxidación-reducción, que se produce por una diferencia de potencial entre el cátodo y el ánodo (Minagar et al., 2012). Sista et al. (2013) observaron un incremento de la adhesión y del crecimiento celular en las superficies anodizadas con respecto a las superficies grabadas con ácido o superficies pulidas.

\subsection{Oxidación electroquímica en electrolitos que presentan iones flúor}

La oxidación electroquímica con electrolitos que contienen iones de flúor, está centrando el interés de los investigadores, dado que permite obtener una capa superficial de óxido de titanio o de otro metal de transición con estructura nanotubular, de forma rápida y con reducido coste (Bauer et al., 2011, Choe 
et al., 2010; Kim et al., 2011; Ferreira et al., 2013). El mecanismo básico para la formación de los nanotubos está compuesto por dos procesos, el primero de ellos es el ataque químico y el segundo la disolución química. El mecanismo comienza con la formación de una capa inicial de óxido en la superficie de la aleación de titanio, debida a la interacción de $\mathrm{Ti}^{4+}$, $\mathrm{Nb}^{5+}, \mathrm{Ta}^{5+}$ y $\mathrm{Zr}^{4+}$ y los iones $\mathrm{O}^{2-}$ (Sista et al., 2013). Sigue con la aparición del fenómeno de corrosión por picadura, éste se produce por la disolución localizada de los iones de $\mathrm{F}^{-}$. Las picaduras en la superficie del implante se convierten en poros de mayor tamaño, este crecimiento ocurre por el desplazamiento de la capa de óxido hacia el interior. El avance de esta oxidación selectiva, que separa unas picaduras de otras, permite la formación de los nanotubos (Berger et al., 2010; Minagar et al., 2012). Si el voltaje aplicado es demasiado elevado se produce el colapso de los nanotubos, tal y como se puede observar en la Fig. 8, obtenida por los autores de este artículo.

Las dimensiones, morfología y estructura de los nanotubos de óxido de titanio pueden ser controladas durante su proceso de fabricación (Choe et al., 2010; Kim et al., 2011; Çalişkan et al., 2014; Jeong et al., 2014a). Estas características dependen de los parámetros electroquímicos (rampa y potencial de anodización), de la naturaleza del electrolito (composición, concentración, $\mathrm{pH}$ y temperatura de la solución) y de las características del sustrato (composición química, estructura) (Bauer et al., 2011; Kim et al., 2013). El diámetro de los nanotubos aumenta al incrementar el voltaje. (Choe et al., 2010, Tan et al., 2012; Hao et al., 2013; Çalişkan et al., 2014). La Fig. 9, obtenida por los autores de este artículo, muestra la capa de nanotubos obtenida para una aleación Ti Cp Grado 2 a 25V.

Los electrolitos orgánicos poseen un contenido de oxígeno menor si se compara con los electrolitos acuosos. Estos tipos de electrolitos, como pueden ser los compuestos por $\mathrm{NH}_{4} \mathrm{~F}$ y glicerol, presentan una menor constante de difusión y este factor tiene influencia en el fenómeno de corrosión por picadura y en la velocidad de disolución de la capa de óxido. Donde la viscosidad del electrolito tiene una gran influencia en la constante de difusión (Minagar et al., 2012). El empleo de estos electrolitos presenta la desventaja de la mayor complejidad en la eliminación de los mismos en etapas posteriores de limpieza y en el mayor tiempo de anodizado para la obtención de nanotubos. El primer motivo hace que los posibles restos viscosos tengan un impacto negativo en etapas posteriores de deposición de elementos bioactivos, como pueden ser el fosfato de calcio o la hidroxiopatita. El segundo motivo, mayores tiempos de anodizado, incrementa el tipo de ciclo para obtención del tratamiento superficial y por lo tanto aumenta el coste de éste.

Estudios in vitro han demostrado que las superficies con capas de óxido de titanio, que presentan geometría de nanotubos, mejoran el crecimiento celular y el crecimiento óseo (Mendonça et al., 2008; Berger et al., 2011; Sista et al., 2013). La

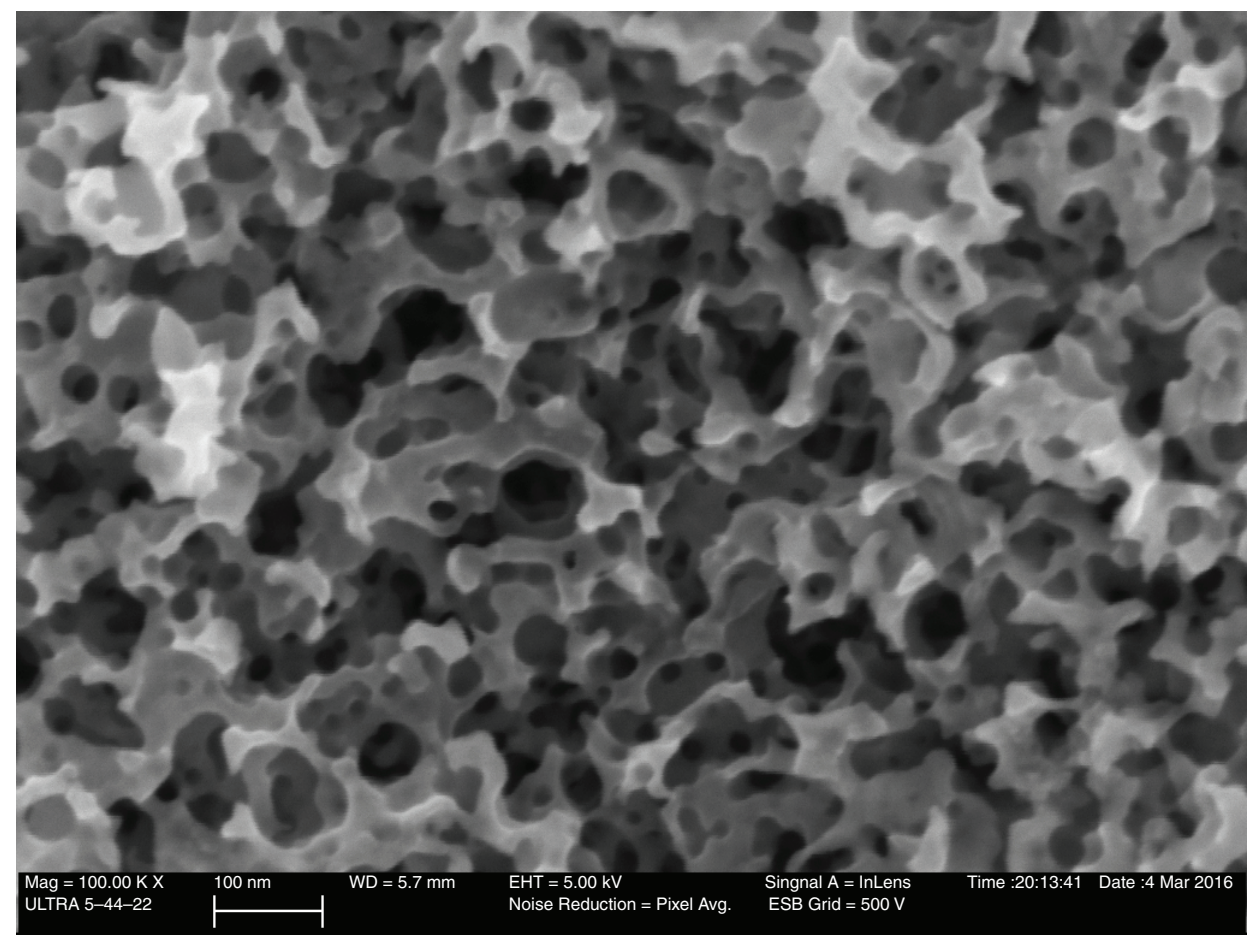

FIgURA 8. Oxidación electroquímica en Ti Cp Grado 2, en un electrolito de $\mathrm{H}_{3} \mathrm{PO}_{4} 1 \mathrm{M}+0,8 \%$ peso NaF y $35 \mathrm{~V}$. 


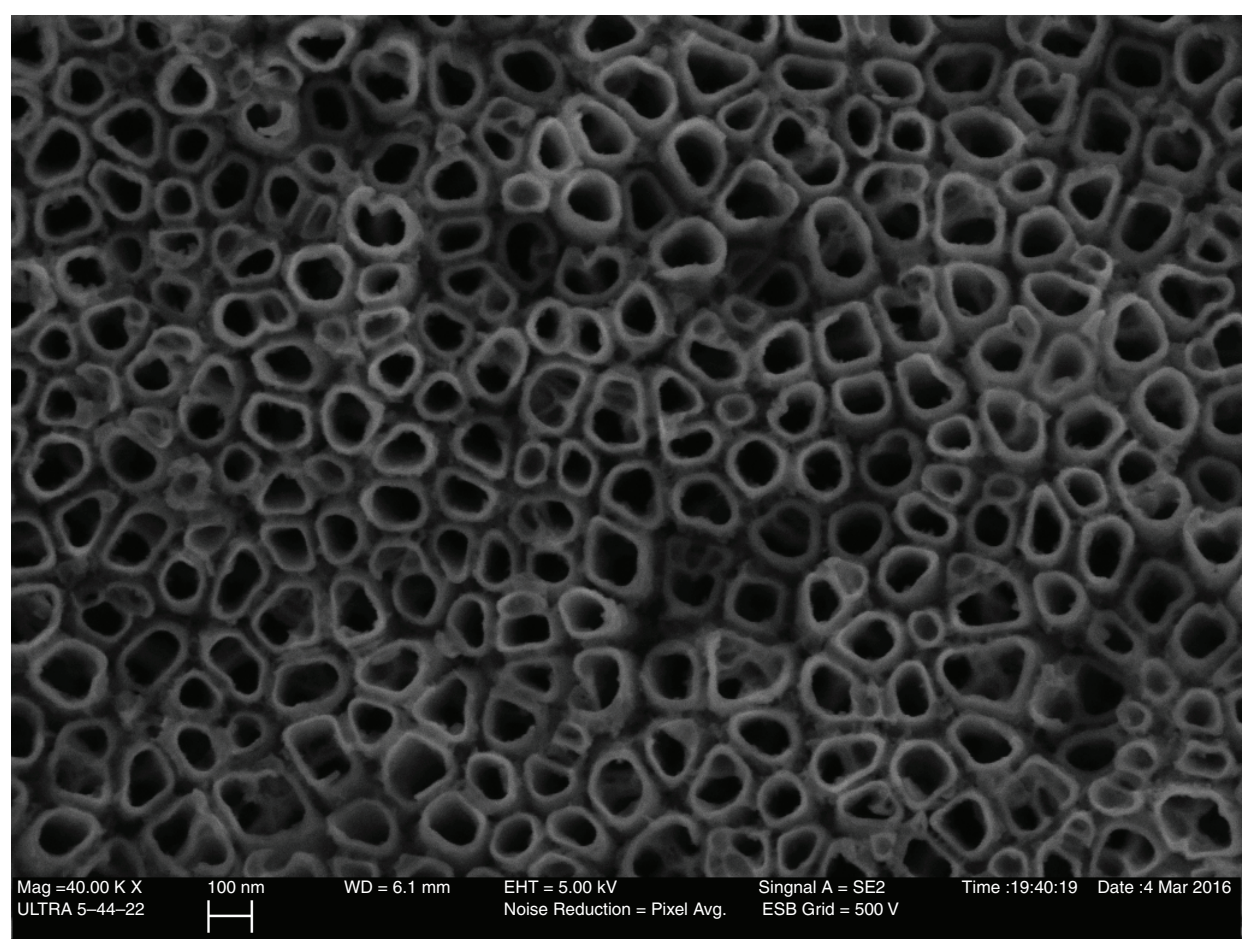

Figura 9. Capa de nanotubos obtenida en Ti Cp Grado 2, en un electrolito de $\mathrm{H}_{3} \mathrm{PO}_{4} 1 \mathrm{M}+0,8 \%$ peso NaF y $25 \mathrm{~V}$.

morfología de los nanotubos de titanio, definida por una nanorugosidad, elevada energía superficial y bajo ángulo de contacto mejoran significativamente el anclaje de las células en el implante (Das et al., 2009). El aumento de la rugosidad en la superficiedel, implante mejora la mojabilidad, favoreciendo la fijación de las células mediante la formación de contactos locales y la absorción de proteínas. Con el tiempo estos implantes con mayor rugosidad se fijan mejor en el lecho del implante, este fenómeno se produce porque el hueso crece dentro de irregularidades de la superficie. Das et al. (2007) demostraron que las superficies de titanio CP con una morfología de nanotubos muestran una mejor adhesión y crecimiento de osteoblastos humanos, así como una excelente morfología para el anclaje de filopodios. Brammer et al. (2009) demostraron que mediante el control de la nanotopografía de las capas de óxido de titanio, obtenidas con diámetros con valores próximos a $100 \mathrm{~nm}$, induce a la adhesión de células con formas elongadas (ratio 11:1), que incrementan la habilidad para la formación del hueso.

Además, este tipo de geometrías pueden incorporar en su interior agentes bioactivos (antibióticos, bactericidas, Ca-P), que se liberan gradualmente en las cercanías del implante, mejorando la osteointegración a corto y largo plazo (Yao y Webster, 2009; Çalişkan et al., 2014; Xie et al., 2014). En la En la Fig. 10, obtenida por los autores de este artículo, se puede observar claramente la morfología de los nanotubos.

La liberación prolongada de medicamentos desde el implante permite atacar al foco de la infección, reduciendo la cantidad de medicamentos suministrados al paciente y minimizando la posibilidad de la toxicidad sistemática de los medicamentos. Dentro de los fármacos que pueden incorporarse en el interior de los nanotubos se encuentran aquellos que pueden combatir infecciones, reducir la inflamación y promover el crecimiento celular para la formación del hueso (Çalişkan et al., 2014). Park et al. (2014) reportaron que las aleaciones beta de titanio implantadas en ratas, con una superficie de nanotubos y donde se le ha precipitado iones de calcio y fosfato poseen un mayor porcentaje de contacto con el hueso y un mayor grado de anclaje del implante. Yao y Webster (2009) fueron capaces de obtener un tratamiento superficial, de nanotubos, con la capacidad de suministrar antibióticos durante largos periodos de tiempo. Los resultados muestran que la precipitación de antibióticos realizado sobre los nanotubos era capaz de suministrar antibióticos hasta las tres semanas.

\subsection{Tratamientos térmicos para modificar la estructura cristalina de las superficies de óxido obtenidos mediante oxidación electroquímica}

El recubrimiento de las superficies de titanio es de unos pocos nanómetros de espesor y está formado principalmente por dióxido de titanio amorfo. Las propiedades físico-químicas y electroquímicas de la capa de óxido, así como la estabilidad a largo plazo en ambientes biológicos, juegan 


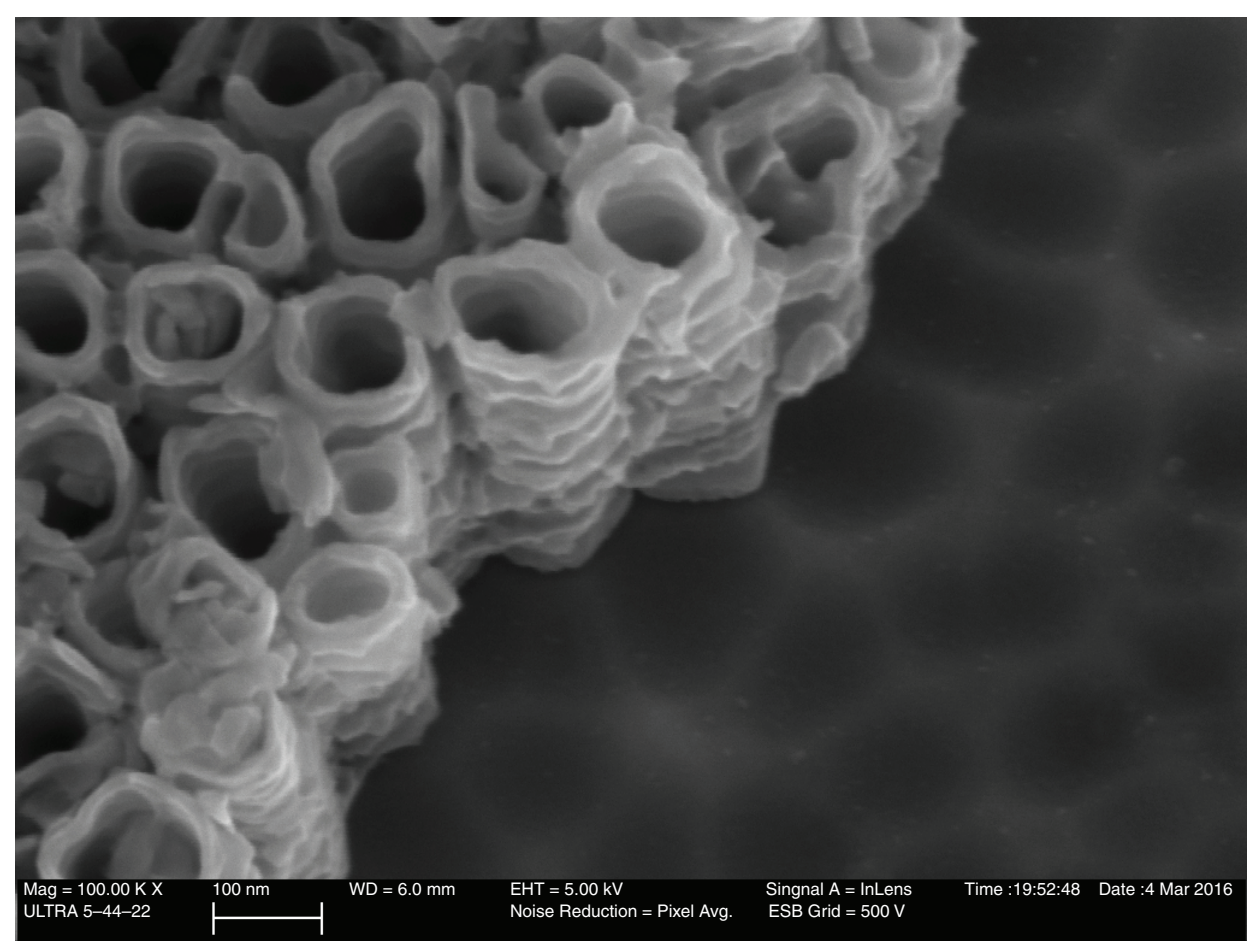

Figura 10. Morfología de los nanotubos obtenida en Ti Cp Grado 2, en un electrolito de $\mathrm{H}_{3} \mathrm{PO}_{4} 1 \mathrm{M}+0,8 \%$ peso $\mathrm{NaF}$ y $25 \mathrm{~V}$.

un papel decisivo en la biocompatibilidad de los implantes de titanio (Yao y Webster, 2009). La estructura cristalina de los nanotubos de titanio influye en la biocompatibilidad, dado que afecta a la resistencia a la corrosión. Las tres estructuras cristalinas más comunes del óxido de titanio son anatasa, rutilo y brookita. Un elevado número de estudios han probado que este tipo de estructuras presentan un efecto positivo en el crecimiento celular, mejorando la adhesión, proliferación y diferenciación de los osteoblastos (Pan et al., 1996; Browne y Gregson., 2000; Reyes-Coronado et al., 2008; Zhao et al., 2010). Por lo que es recomendable realizar un tratamiento térmico a los nanotubos para ser empleados en materiales para implantes (Kim et al., 2011).

La estructura amorfa obtenida en el proceso de oxidación anódica se puede modificar realizando un tratamiento térmico posterior a la obtención de los nanotubos. Bai et al. (2011) reportaron que los nanotubos de titanio pueden transformarse de amorfos a estructura anatasa a temperaturas superiores a $300{ }^{\circ} \mathrm{C}$, y en una mezcla de anatasa y rutilo a una temperatura superior a $450{ }^{\circ} \mathrm{C}$. Los tratamientos térmicos donde se alcanzan temperaturas superiores a los $650{ }^{\circ} \mathrm{C}$, tienen efectos adversos en la estabilidad estructural. Al sobrepasar esta temperatura la elevada área superficial provoca que se alcance el estado sólido de sinterizado, lo que conlleva un crecimiento de grano, densificación y un posible derrumbe o colapso de la estructura.
Yu et al. (2010) y Bai et al. (2011) llevaron a cabo diferentes tratamientos térmicos para evaluar el crecimiento de los osteoblastos en nanotubos con diferentes estructuras cristalinas. Los resultados mostraron que el crecimiento celular en la superficie de los nanotubos seguía la siguiente tendencia anatasa-rutilo > anatasa > amorfo (Tan et al., 2012). El tratamiento térmico para la obtención de la estructura cristalina en los nanotubos también es útil para eliminar las toxinas, como puede ser el flúor, que permanecen en la superficie de la aleación y que pueden ser tóxicas para el huésped.

\subsection{Tratamientos bioactivos}

Paralelamente a los tratamientos superficiales como plasma espray, arenado, grabado ácido o la oxidación electroquímica, ya vistos, se han desarrollado recubrimientos con materiales bioactivos, como la hidroxipatita o fosfato de calcio, para mejorar la biocompatibilidad de las superficies de titanio (Choe et al., 2010; Çalişkan et al., 2014; Xie et al., 2014). Aunque estos recubrimientos superficiales presentan una elevada área superficial y bioactividad, tienden a delaminarse en la interfase entre el implante y el hueso debido a la diferencia de espesor y propiedades entre la capa de óxido de titanio y el recubrimiento bioactivo. La adhesión del recubrimiento de $\mathrm{CaP}$ al sustrato de titanio es pobre, debido a las diferencias entre el módulo elástico y el coeficiente de expansión térmica que hay entre ambos materiales. Estas diferencias 
generan tensiones interfaciales que pueden provocar el fallo del recubrimiento (Duraccio et al., 2015). En los últimos años está cobrando gran interés el estudio de este tipo de recubrimientos en las superficies de titanio con morfología de nanotubos. La principal ventaja de estos nuevos sustratos es la reducción de la concentración de tensiones interfaciales y la mejora de la adhesión (Berger et al., 2011; Tan et al., 2012; Jeong et al., 2014b).

\section{CONCLUSIONES}

- El empleo de las aleaciones $\beta$ de titanio mejora la vida útil de prótesis metálicas si se compara con las aleaciones $\alpha$ o $\alpha+\beta$ de titanio utilizadas en la actualidad. Estas aleaciones $\beta$ presentan una mayor compatibilidad mecánica con el hueso, gracias a su bajo módulo elástico, alta resistencia a la rotura y elevada resistencia a fatiga. El empleo de estas aleaciones reduce el efecto de apantallamiento de tensiones, que provoca reabsorción ósea en el hueso cercano a la prótesis y que merma la vida útil del implante. Además, esta familia de aleaciones está compuesta con elementos biocompatibles, como son el $\mathrm{Nb}$, Ta y $\mathrm{Zr}$, que aumentan la resistencia a la corrosión de la aleación y reducen la posibilidad de reacciones sistemáticas del cuerpo.

- También cabe destacar que el tratamiento superficial que mayor tasa de osteointegración consigue es la oxidación electroquímica, en electrolitos que presentan iones de flúor. Este tratamiento permite obtener una capa superficial de óxido de titanio, o de otro metal de transición, con estructura nanotubular de forma rápida y con reducido coste de fabricación. La rugosidad superficial a escala nanométrica mejora el crecimiento óseo y el contacto entre el hueso e implante, si se compara con las técnicas tradicionales de arenado o grabado ácido. Con el tiempo, estos implantes, con morfología de nanotubos, se fijan mejor y aumentan la vida útil de la prótesis.

- El empleo de post tratamientos térmicos para la obtención de una estructura cristalina en los nanotubos mejora la resistencia a la corrosión de los biomateriales, traduciéndose en una mejora del crecimiento celular y el aumento de la vida útil de la prótesis.

\section{AGRADECIMIENTOS}

Los autores desean agradecer al Ministerio de Economía y competitividad el apoyo financiero a través del proyecto de investigación MAT201453764-C3-1-R y a la Generalitat Valenciana a través del apoyo PROMETEO/2016/040. A la Comisión Europea a través de los fondos FEDER que han permitido la adquisición de los equipos para la investigación y del Servicio de Microscopía de la Universitat Politècnica de València.

\section{REFERENCIAS}

Ahmed, T., Rack, H.J. (1998). Phase transformations during cooling in $\alpha+\beta$ titanium alloys. Mat. Sci. Eng. A-Struct. 243 (1-2), 206-211. http://dx.doi.org/10.1016/ S0921-5093(97)00802-2.

Anselme, K., Bigerelle, M., Noel, B., Dufresne, E., Judas, D., Iost, A., Hardouin, P. (2000). Qualitative and quantitative study of human osteoblast adhesion on materials with various surface roughnesses. J. Biomed. Mater. Res. 49 (2), 155-166. http://dx.doi.org/10.1002/(SICI)10974636(200002)49:2<155::AID-JBM2>3.0.CO;2-J.

Bai, Y., Park, I.S., Park, H.H., Lee, M.H., Bae, T.S., Duncan, W., Swain, M. (2011). The effect of annealing temperatures on surface properties, hydroxyapatite growth and cell behaviors of $\mathrm{TiO}_{2}$ nanotubes. Surf. Interface Anal. 43 (6), 998-1005. http://dx.doi.org/10.1002/sia.3683.

Ban, S., Iwaya, Y., Kono, H., Sato, H. (2006). Surface modification of titanium by etching in concentrated sulfuric acid. Dent. Mater. 22 (12), 1115-1120. http://dx.doi. org/10.1016/j.dental.2005.09.007.

Bauer, S., Pittrof, A., Tsuchiya, H., Schmuki, P. (2011). Sizeeffects in $\mathrm{TiO}_{2}$ nanotubes: Diameter dependent anatase/ rutile stabilization. Electrochem. Commun. 13 (6), 538-541. http://dx.doi.org/10.1016/j.elecom.2011.03.003.

Bayram, C., Demirbilek, M., Yalçin, E., Bozkurt, M., Doğan, M., Denkbaş, E.B. (2014). Osteoblast response on comodified titanium surfaces via anodization and electrospinning. Appl. Surf. Sci. 288, 143-148. http://dx.doi. org/10.1016/j.apsusc.2013.09.168.

Berger, S., Hahn, R., Roy, P., Schmuki, P. (2010). Self-organized $\mathrm{TiO}_{2}$ nanotubes: Factors affecting their morphology and properties. Phys. Status Solidi B 247 (10), 2424-2435. http://dx.doi.org/10.1002/pssb.201046373.

Berger, S., Albu, S.P., Schmidt-Stein, F., Hildebrand, H., Schmuki, P., Hammond, J.S., Reichlmaier, S. (2011). The origin for tubular growth of $\mathrm{TiO}_{2}$ nanotubes: A fluoride rich layer between tube-walls. Surf. Sci. 605 (19-20), L57-L60. http://dx.doi.org/10.1016/j.susc.2011.06.019.

Bjursten, L.M., Rasmusson, L., Oh, S., Smith, G.C., Brammer, K.S., Jin, S. (2010). Titanium dioxide nanotubes enhance bone bonding in vivo. J. Biomed. Mater. Res. - A 92A (3), 1218-1224. http://dx.doi.org/10.1002/jbm.a.32463.

Brammer, K.S., Oh, S., Cobb, C.J., Bjursten, L.M., Heyde, H. Van Der, Jin, S. (2009). Improved bone-forming functionality on diameter-controlled $\mathrm{TiO}_{2}$ nanotube surface. Acta Biomater. 5 (8), 3215-3223. http://dx.doi.org/10.1016/j. actbio.2009.05.008.

Browne, M., Gregson, P.J. (2000). Effect of mechanical surface pretreatment on metal ion release. Biomaterials 21 (4), 385392. http://dx.doi.org/10.1016/S0142-9612(99)00200-8.

Calișkan, N., Bayram, C., Erdal, E., Karahaliloğlu, Z., Denkbas, E.B. (2014). Titania nanotubes with adjustable dimensions for drug reservoir sites and enhanced cell adhesion. Mat. Sci. Eng. C 35, 100-105. http://dx.doi.org/10.1016/j. msec.2013.10.033.

Chlebus, E., Kuźnicka, B., Kurzynowski, T., Dybała, B. (2011). Microstructure and mechanical behaviour of Ti-6Al-7Nb alloy produced by selective laser melting. Mater. Charact. 62 (5), 488-495. http://doi.org/10.1016/j. matchar.2011.03.006

Choe, H.C., Kim, W.G., Jeong, Y.H. (2010). Surface characteristics of $\mathrm{HA}$ coated $\mathrm{Ti}-30 \mathrm{Ta}-\mathrm{xZr}$ and $\mathrm{Ti}-30 \mathrm{Nb}-$ $\mathrm{xZr}$ alloys after nanotube formation. Surf. Coat. Tech. 205 (Suppl. 1), S305-S311. http://dx.doi.org/10.1016/j. surfcoat.2010.08.020.

Cochran, D.L., Schenk, R.K., Lussi, A., Higginbottom, F.L., Buser, D. (1998). Bone response to unloaded and loaded titanium implants with a sandblasted and acid-etched surface: A histometric study in the canine mandible. J. Biomed. Mater. Res. 40 (1), 1-11. http://dx.doi.org/10.1002/ (SICI)1097-4636(199804)40:1<1::AID-JBM1>3.0.CO;2-Q. 
Cremasco, A., Osório, W.R., Freire, C.M., Garcia, A., Caram, R. (2008). Electrochemical corrosion behavior of a Ti-35Nb alloy for medical prostheses. Electrochim. Acta 53 (14), 4867-4874. http://dx.doi.org/10.1016/j. electacta.2008.02.011.

Cremasco, A., Messias, A.D., Esposito, A.R., Duek, E.A.D.R., Caram, R. (2011). Effects of alloying elements on the cytotoxic response of titanium alloys. Mat. Sci. Eng. C 31 (5), 833-839.

Das, K., Bose, S., Bandyopadhyay, A. (2007). Surface modifications and cell-materials interactions with anodized $\mathrm{Ti}$. Acta Biomater. 3 (4), 573-585. http://dx.doi.org/10.1016/j. actbio.2006.12.003.

Das, K., Bose, S., Bandyopadhyay, A. (2009). $\mathrm{TiO}_{2}$ nanotubes on Ti: Influence of nanoscale morphology on bone cellmaterials interaction. J. Biomed. Mater. Res. A 90A (1), 225-237. http://dx.doi.org/10.1002/jbm.a.32088.

Diniz, M.G., Soares, G.A., Coelho, M.J., Fernandes, M.H. (2002). Surface topography modulates the osteogenesis in human bone marrow cell cultures grown on titanium samples prepared by a combination of mechanical and acid treatments. J. Mater. Sci. - Mater. M. 13 (4), 421-432. http://dx.doi.org/10.1023/A:1014357122284

Duraccio, D., Mussano, F., Faga, M.G. (2015). Biomaterials for dental implants: current and future trends. $J$. Mater. Sci. 50 (14), 4779-4812. http://dx.doi.org/10.1007/ s10853-015-9056-3.

Eisenbarth, E., Velten, D., Müller, M., Thull, R., Breme, J. (2004). Biocompatibility of $\beta$-stabilizing elements of titanium alloys. Biomaterials 25 (26), 5705-5713. http://dx.doi. org/10.1016/j.biomaterials.2004.01.021

Ferreira, C.P., Gonçalves, M.C., Caram, R., Bertazzoli, R., Rodrigues, C.A. (2013). Effects of substrate microstructure on the formation of oriented oxide nanotube arrays on $\mathrm{Ti}$ and Ti alloys. Appl. Surf. Sci. 285 (Part B), 226-234. http:// dx.doi.org/10.1016/j.apsusc.2013.08.041.

Han, C.M., Kim, H.E., Koh, Y.H. (2014). Creation of hierarchical micro/nano-porous $\mathrm{TiO}_{2}$ surface layer onto $\mathrm{Ti}$ implants for improved biocompatibility. Surf. Coat. Tech. 251, 226-231. http://dx.doi.org/10.1016/j. surfcoat.2014.04.030.

Hao, Y.Q., Li, S.J., Hao, Y.L., Zhao, Y.K., Ai, H.J. (2013). Effect of nanotube diameters on bioactivity of a multifunctional titanium alloy. Appl. Surf. Sci. 268, 44-51. http://dx.doi. org/10.1016/j.apsusc.2012.11.142.

Iijima, D., Yoneyama, T., Doi, H., Hamanaka, H., Kurosaki, N. (2003). Wear properties of Ti and Ti-6Al-7Nb castings for dental prostheses. Biomaterials 24 (8), 1519-1524. http:// dx.doi.org/10.1016/S0142-9612(02)00533-1.

Jeong, Y.H., Kim, W.G., Choe, H.C., Brantley, W.A. (2014a). Control of nanotube shape and morphology on $\mathrm{Ti}-$ $\mathrm{Nb}(\mathrm{Ta})-\mathrm{Zr}$ alloys by varying anodizing potential. Thin Solid Films 572, 105-112. http://dx.doi.org/10.1016/j. tsf.2014.09.057.

Jeong, Y.H., Kim, E.J., Brantley, W.A., Choe, H.C. (2014b). Morphology of hydroxyapatite nanoparticles in coatings on nanotube-formed $\mathrm{Ti}-\mathrm{Nb}-\mathrm{Zr}$ alloys for dental implants. Vacuum 107, 297-303. http://dx.doi.org/10.1016/j. vacuum.2014.03.004

Kim, W.G., Choe, H.C., Brantley, W.A. (2011). Nanostructured surface changes of Ti-35Ta-xZr alloys with changes in anodization factors. Thin Solid Films 519 (15), 4663-4667. http://dx.doi.org/10.1016/j.tsf.2011.01.013

Kim, E.S., Jeong, Y. H., Choe, H.C., Brantley, W. A (2013). Formation of titanium dioxide nanotubes on Ti-30Nb-xTa alloys by anodizing. Thin Solid Films 549, 141-146. http:// dx.doi.org/10.1016/j.tsf.2013.08.058.

Kuroda, D., Niinomi, M., Morinaga, M., Kato, Y., Yashiro, T. (1998). Design and mechanical properties of new $\beta$ type titanium alloys for implant materials. Mat. Sci. Eng. A-Struct. 243 (1-2), 244-249. http://dx.doi.org/10.1016/ S0921-5093(97)00808-3.

Le Guehennec, L., Soueidan, A., Layrolle, P., Amouriq, Y. (2007). Surface treatments of titanium dental implants for rapid osseointegration. Dent. Mater. 23 (7), 844-854. http://dx.doi.org/10.1016/j.dental.2006.06.025.
Le Guehennec, L., Lopez-Heredia, M.-A., Enkel, B., Weiss, P., Amouriq, Y., Layrolle, P. (2008). Osteoblastic cell behaviour on different titanium implant surfaces. Acta Biomater. 4 (3), 535-543. http://dx.doi.org/10.1016/j.actbio.2007.12.002.

Lee, K., Jeong, Y.H., Ko, Y.M., Choe, H.C., Brantley, W.A (2013). Hydroxyapatite coating on micropore-formed titanium alloy utilizing electrochemical deposition. Thin Solid Films 549, 154-158. http://dx.doi.org/10.1016/j. tsf.2013.09.002.

Lee, W.S., Chen, C.W. (2013). High temperature impact properties and dislocation substructure of Ti-6Al-7 Nb biomedical alloy. Mat. Sci. Eng. A-Struct. 576, 91-100. http:// dx.doi.org/10.1016/j.msea.2013.03.088.

Li, D., Ferguson, S.J., Beutler, T., Cochran, D.L., Sittig, C., Hirt, H.P. Buser, D. (2002). Biomechanical comparison of the sandblasted and acid-etched and the machined and acidetched titanium surface for dental implants. J. Biomed. Mater. Res. - 60 (2), 325-332. http://dx.doi.org/10.1002/ jbm.10063.

Long, M., Rack, H.J. (1998). Titanium alloys in total joint replacement--a materials science perspective. Biomaterials 19 (18), 1621-1639. http://dx.doi.org/10.1016/ S0142-9612(97)00146-4.

Lütjering, G. (1998). Influence of processing on microstructure and mechanical properties of $(\alpha+\beta)$ titanium alloys. Mat. Sci. Eng. A-Struct. 243 (1-2), 32-45. http://dx.doi. org/10.1016/S0921-5093(97)00778-8.

Mendonça, G., Mendonça, D.B.S., Aragão, F.J.L., Cooper, L.F. (2008). Advancing dental implant surface technology - From micron-to nanotopography. Biomaterials 29 (28), 3822-3835. http://dx.doi.org/10.1016/j. biomaterials.2008.05.012.

Minagar, S., Berndt, C.C., Wang, J., Ivanova, E., Wen, C. (2012). A review of the application of anodization for the fabrication of nanotubes on metal implant surfaces. Acta Biomater. 8 (8), 2875-2888. http://dx.doi.org/10.1016/j. actbio.2012.04.005

Minagar, S., Wang, J., Berndt, C.C., Ivanova, E.P., Wen, C. (2013). Cell response of anodized nanotubes on titanium and titanium alloys. J. Biomed. Mater. Res. $A$ 101A (9), 2726-2739. http://dx.doi.org/10.1002/jbm.a.34575.

Mîndroiu, M., Pirvu, C., Ion, R., Demetrescu, I. (2010). Comparing performance of nanoarchitectures fabricated by Ti6Al7Nb anodizing in two kinds of electrolytes. Electrochim. Acta 56 (1), 193-202. http://dx.doi.org/10.1016/j. electacta.2010.08.100.

National Center for Health Statistics (2015). Health, United States, With Special Feature on Adults Aged 55-64, DHHS Publication $\mathrm{N}^{\mathrm{o}} 2015-1232$

Nguyen, T.D.T., Park, I.S., Lee, M.H., Bae, T.S. (2013). Enhanced biocompatibility of a pre-calcified nanotubular $\mathrm{TiO}_{2}$ layer on Ti-6Al-7Nb alloy. Surf. Coat. Tech. 236, 127-134. http://dx.doi.org/10.1016/j.surfcoat.2013.09.038.

Niinomi, M. (1998). Mechanical properties of biomedical titanium alloys. Mat. Sci. Eng. A-Struct. 243 (1-2), 231-236. http://dx.doi.org/10.1016/S0921-5093(97)00806-X.

Niinomi, M. (2008). Mechanical biocompatibilities of titanium alloys for biomedical applications. J. Mech. Behav. Biomed. Mater. 1 (1), 30-42. http://dx.doi.org/10.1016/j. jmbbm.2007.07.001

Okazaki, Y., Gotoh, E. (2005). Comparison of metal release from various metallic biomaterials in vitro. Biomaterials 26 (1), 11-21. http://dx.doi.org/10.1016/j. biomaterials.2004.02.005.

Ossowska, A., Sobieszczyk, S., Supernak, M., Zielinski, A. (2014). Morphology and properties of nanotubular oxide layer on the "Ti-13Zr-13Nb" alloy. Surf. Coat. Tech. 258, 12391248. http://dx.doi.org/10.1016/j.surfcoat.2014.06.054.

Pan, J., Thierry, D., Leygraf, C. (1996). Electrochemicalimpedance spectroscopy study of the passive oxide film on titanium for implant application. Electrochim. Acta 41 (7-8), 1143 1153. http://dx.doi.org/10.1016/0013-4686(95)00465-3.

Park, I.-S., Bae, T.-S. (2014). The bioactivity of enhanced Ti-32 $\mathrm{Nb}-5 \mathrm{Zr}$ alloy with anodic oxidation and cyclic calcification. Int. J. Precis. Eng. Man. 15 (8), 1595-1600. http:// dx.doi.org/10.1007/s12541-014-0508-5. 
Pypen, C.M.J.M., Plenk, H., Ebel, M.F., Svagera, R., Wernisch, J. (1997). Characterization of microblasted and reactive ion etched surfaces on the commercially pure metals niobium, tantalum and titanium. J. Mater. Sci. - Mater. M. 8 (12), 781-784. http://dx.doi.org/10.1023/A:1018568830442.

Reyes-Coronado, D., Rodríguez-Gattorno, G., Espinosa-Pesqueira, M.E., Cab, C., de Coss, R., Oskam, G. (2008). Phase-pure $\mathrm{TiO}_{2}$ nanoparticles: anatase, brookite and rutile. Nanotechnology 19 (14), 145605. http://dx.doi. org/10.1088/0957-4484/19/14/145605.

Ryan, G., Pandit, A., Apatsidis, D.P. (2006). Fabrication methods of porous metals for use in orthopaedic applications. Biomaterials 27 (13), 2651-2670. http://dx.doi.org/10.1016/j. biomaterials.2005.12.002.

Salou, L., Hoornaert, A., Louarn, G., Layrolle, P. (2015). Enhanced osseointegration of titanium implants with nanostructured surfaces: An experimental study in rabbits. Acta Biomater. 11, 494-502. http://dx.doi.org/10.1016/j. actbio. 2014.10.017

Semiatin, S.L., Ivasishin, O.M., Markovsky, P.E. Shevchenko, S.V., Ulshin, S.V. (2002). Grain growth and texture evolution in Ti A 6Al A 4V during beta annealing under continuous heating conditions. Mat. Sci. Eng. A-Struct. 337 (1-2), 88-96. http://dx.doi.org/10.1016/S0921-5093(01)01990-6.

Sieniawski, J., Filip, R., Ziaja, W. (1997). The effect of microstructure on the mechanical properties of two-phase titanium alloys. Mater. Design 18 (4-6), 361-363. http://dx.doi. org/10.1016/S0261-3069(97)00087-3.
Sista, S., Nouri, A., Li, Y., Wen, C., Hodgson, P.D., Pande, G. (2013). Cell biological responses of osteoblasts on anodized nanotubular surface of a titanium-zirconium alloy. $J$. Biomed. Mater. Res. $-A 101$ (12), 3416-3430. http://dx.doi. org/10.1002/jbm.a.34638.

Tan, A.W. Pingguan-Murphy, B., Ahmad, R., Akbar, S.A. (2012). Review of titania nanotubes: Fabrication and cellular response. Ceram. Int. 38 (6), 4421-4435. http://dx.doi. org/10.1016/j.ceramint.2012.03.002.

Xie, Y., Ao, H., Xin, S., Zheng, X., Ding, C. (2014). Enhanced cellular responses to titanium coating with hierarchical hybrid structure. Mat. Sci. Eng. C 38, 272-277. http:// dx.doi.org/10.1016/j.msec.2014.02.004

Yao, C., Webster, T.J. (2009). Prolonged antibiotic delivery from anodized nanotubular titanium using a co-precipitation drug loading method. J. Biomed. Mater. Res.-B 91B (2), 587-595. http://dx.doi.org/10.1002/jbm.b.31433.

Yu, W.Q, Zhang, Y.L., Jiang, X.Q., Zhang, F.Q. (2010). In vitro behavior of MC3T3-E1 preosteoblast with different annealing temperature titania nanotubes. Oral Dis. 16(7), 624-630. http://dx.doi.org/10.1111/j.1601-0825.2009.01643.x

Zhao, Y., Xiong, T., Huang, W. (2010). Effect of heat treatment on bioactivity of anodic titania films. Appl. Surf. Sci. 256 (10), 3073-3076. http://dx.doi.org/10.1016/j. apsusc. 2009.11.075.

18th CEIES Seminar (2002). Active ageing statistics, ISBN: 92-8943296-9, Ed. European Commission, La Haya. http://bookshop. europa.eu/en/18th-ceies-seminar-pbKSPB02006/. 